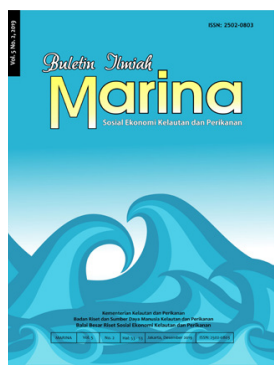

BULETIN ILMIAH MARINA

SOSIAL EKONOMI KELAUTAN DAN PERIKANAN

http://ejournal-balitbang.kkp.go.id/index.php/mra

p-ISSN: 2502-0803

e-ISSN: 2541-2930

Nomor Akreditasi: 30/E/KPT/2019

\title{
ANALISIS KESIAPAN SENTRA KELAUTAN PERIKANAN TERPADU (SKPT) PULAU MOA SEBAGAI SENTRA PERIKANAN DI MALUKU BARAT DAYA
}

\section{Readiness Analysis of The Integrated Marine and Fisheries Center (IMFC) in Moa Island as Fisheries Center in South West Maluku}

\author{
*Permana Ari Soejarwo, Umi Muawanah dan Bayu Vita Indah Yanti \\ Balai Besar Riset Sosial Ekonomi Kelautan dan Perikanan \\ Gedung BRSDM KP I Lt. 4, Jln. Pasir Putih Nomor 1 Ancol Timur, Jakarta Utara, Indonesia \\ Telp: (021) 64711583 Fax: 64700924
}

Diterima tanggal: 6 Agustus 2019 Diterima setelah perbaikan: 10 Oktober 2019

Disetujui terbit: 20 November 2019

\begin{abstract}
ABSTRAK
Pembangunan Sentra Kelautan Perikanan Terpadu (SKPT) Pulau Moa akan direalisasikan dengan adanya rencana Pengembangan infrastruktur serta sarana prasana pendukung kegiatan kelautan perikanan. SKPT berpotensi dalam meningkatkan kegiatan penangkapan dan pemrosesan perikanan di Maluku Barat Daya (MBD). Penelitian ini bertujuan untuk menganalisis kesiapan SKPT Moa sebagai salah satu sentra industri perikanan di pulau terluar Indonesia dengan metode deskritif kualitatif. Data dan informasi primer dikumpulkan melalui observasi lapangan, wawancara mendalam dengan Dinas Kelautan dan Perikanan Kabupaten Maluku Barat Daya, nelayan dan perangkat desa. Pengumpulan data sekunder diperoleh dari berbagai instansi terkaityang berhubungan dengan penelitian. Hasil penelitian ini menunjukkan bahwa aspek yang diteliti pada kesiapan SKPT Moa meliputi kesiapan infrastruktur, sarana dan prasaran, kelembagaan, dan pemanfaatan sumber daya kelautan perikanan. Strategi persiapan SKPT Moa antara lain dengan: 1) Percepatan pembangunan infrastruktur SKPT Moa seperti listrik, air bersih, jalan, telekomunikasi, bandar udara dan pelabuhan; 2) Pembentukan dan penguatan kelembagaan non formal dan formal dalam pengelola aset produktif SKPT, 3) Percepatan dalam optimalisasi pemanfaatan sumberdaya kelautan perikanan. Hal ini dipertimbangkan dari sisi alat tangkap dan armada, pelatihan dan pendampingan terhadap nelayan, serta komunikasi dan konsolidasi dengan pengelola WPP 714 di tingkat regional dan tingkat propinsi.
\end{abstract}

Kata Kunci: Maluku Barat Daya; perikanan tangkap; Pulau MOA; SKPT

\begin{abstract}
The development of Integrated Marine and Fisheries Center (IMFC), so called IMFC in Moa Island will be realized through the ingrastructure establshement and supporting facilites supporting marine and fisheries activitites. IMFC has the potentisla to increase the capture fisheries and fish processing development in Southwest Maluku (Maluku Barat Daya, MBD). This study aims to analyse the readiness level of IMFC Moa as one of the fisheries industries center using qualitative descriptive method. Data was gathered thorugh field observation, in depth interview with fishers, fisheries offices at MBD and village officers. Secondary data was collected from relevant offices in MBD. The study analyses several aspects including infrastructure, facilities, governance, marine resource utilizstion. Several strategies to speed up the IMFC readiness are: 1) Acceleration of IMFC basic infrastructures such as electricity, clean water, road, telecommunicaiton, airport, and fishing ports;2) Development and Stregtherning the formal and non-formal finansial institution to manage IMFC productive assets; 3) Acceleration of optimal utilization of fisheries resources. This should considers the types of fishing gears and vessels, provide capacity buildings for the fisheres and smooth coordination with manager of the WPP institution at WPP 714 at regional and provincial level.
\end{abstract}

Keywords: South West Maluku; capture fisheries; Island MOA; SKPT; 


\section{PENDAHULUAN}

Sentra Kelautan Perikanan Terpadu (SKPT) merupakan salah satu implementasi program Nawa Cita ketiga yang dicanangkan oleh Presiden Joko Widodo. Program ini menitik beratkan pada wilayah laut dan pulau-pulau kecil dengan semangat "Laut adalah masa depan bangsa dan membangun Indonesia dari pinggiran dengan memperkuat daerah-daerah dan desa dalam kerangka negara kesatuan". Lebih lanjut Nawacita ketiga tersebut masuk dalam rancangan dasar hukum Pembangunan Industri Perikanan Nasional yang terdapat pada Instruksi Presiden (Inpres) Nomor 7 Tahun 2016, serta dijabarkan dalam Peraturan Presiden Republik Indonesia Nomor 3 Tahun 2017 tentang Rencana Aksi Percepatan Pembangunan Industri Perikanan Nasional.

Konsep pembangunan SKPT dilakukan dengan pendekatan berbasis wilayah, budaya dan bisnis yang saling berkaitan satu sama lain sehingga terwujud mata rantai yang tidak dapat dipisahkan. Hal ini merupakan implementasi dari UUD Nomor 32 tahun 2014 dengan prinsip integritas, efesiensi, kualitas dan akselerasi tinggi. SKPT mempunyai visi untuk melakukan percepatan kesejahteraan masyarakat melalui pembangunan pulau mandiri dan terpadu yang bersumber dari sektor kelautan dan perikanan. Salah satu pulau kecil yang akan dikembangkan dengan konsep SKPT yaitu Pulau Moa, Maluku Barat Daya. Menurut Riyadi (2000) pembangunan daerah melalui pengembangan wilayah ditujukan untuk mengupayakan keserasian dan keseimbangan pembangunan antara daerah sesuai dengan potensi alamnya dan memanfaatkan potensi tersebut secara efisien, tertib dan aman. Lebih lanjut disebutkan bahwa dalam konsep pembentukan Kawasan Ekonomi Khusus (KEK) juga dibutuhkan persiapan yang menyeluruh serta komitmen dari seluruh masyarakat yang berkepentingan dalam mendukung pelaksanaan kegiatan di dalam kawasan tersebut. Persiapan yang meliputi kebijakan dan kelembagaan, insentif dan pembiayaan serta dukungan infrastruktur yang sesuai dengan tata ruang wilayah (Wardono et al., 2017). Ppengembangan sektor perikanan tidak hanya terkait dalam usaha perikanan tangkap maupun budidaya. Peluang bisnis kelautan dan perikanan dapat dilihat dari dua aspek yaitu aspek internal termasuk diantara yaitu sumber daya kelautan dan perikanan, sumber daya manusia, teknologi, sarpras serta pemasaran dan aspek ekternal termasuk didalamnya yaitu permintaan produk perikanan dan syarat-syarat yang menyertai permintaan tersebut dalam rangka persaingan (Hendri, 2010). Berdasarkan Wilayah Pengelolaan Perikanan Republik Indonesia (WPP-RI), Pulau Moa masuk dalam WPP 714. Potensi perikanan di WPP 714 sesuai dengan KEPMEN No 47 Tahun 2016 tergolong masih cukup besar, dengan total 431.069 ton. Sementara itu, jumlah tangkapan diperbolehkan sebesar 344.855 ton yang terdiri dari jenis ikan karang, demersal dan pelagis kecil. Ketiga jenis kelompok ikan tersebut mempunyai potensi terbesar di Pulau Moa. Suman, Wudianto, Sumiono, Badrudin \& Nugroho (2014) menyatakan hal yang senada bahwa jenis ikan karang dan ikan demersal di laut Banda penangkapannya masih dapat dikembangkan. Beberapa jenis ikan potensial yang terdapat di Pulau Moa antara lain kerapu, krai, teri, ekor kuning/pisang-pisang, selar, kembung, udang putih/jerbung, udang windu, kepiting, rajungan, cumi-cumi dan sotong (Soejarwo, Muawanah \& Yanti, 2018)

Guna mendukung pembangunan SKPT Pulau Moa pemerintah pusat direncanakan akan memberikan bantuan infrastruktur serta sarana dan prasarana. Salah satu bentuk bantuan tersebut adalah integrated cold storage (ICS) yang berfungsi sebagai penampung ikan dan menjaga kualitas ikan (Soejarwo, Muawanah \& Yanti, 2018). Pembangunan infrastruktur yang dilakukan diPulau Moa difokuskan untuk menunjang kegiatan masyarakat nelayan, seperti ketersediaan akses jalan, listrik, bahan bakar, air bersih, rumah singgah nelayan serta kebutuhan logistik (Permen KP 46/2015). Namun demikian, masih terdapat permasalahan mendasar antara lain 1) Kurangnya kelembagaan usaha nelayan di Pulau Moa seperti kelompok usaha bersama (KUB), Koperasi dan lembaga finansial; 2) Pemasaran hasil perikanan dilakukan secara lokal dan tradisional yaitu melalui papalele (pedagang ikan); 3) Sumber daya ikan ekonomis tinggi belum dapat dimanfaatkan secara optimal karena penggunaan alat tangkap yang sederhana serta mayoritas armada kapal penangkap ikan yang masih berukuran kecil (sekitar 1-5 GT). Oleh karena itu, diperlukan penelitian untuk melakukan analisis kesiapan SKPT Moa sebagai sentra perikanan di Maluku Barat Daya.

Penelitian ini dilakukan di Pulau Moa, Provinsi Maluku Barat Daya pada bulan Agustus November 2018. Peta lokasi penelitian disajikan pada Gambar 1. 


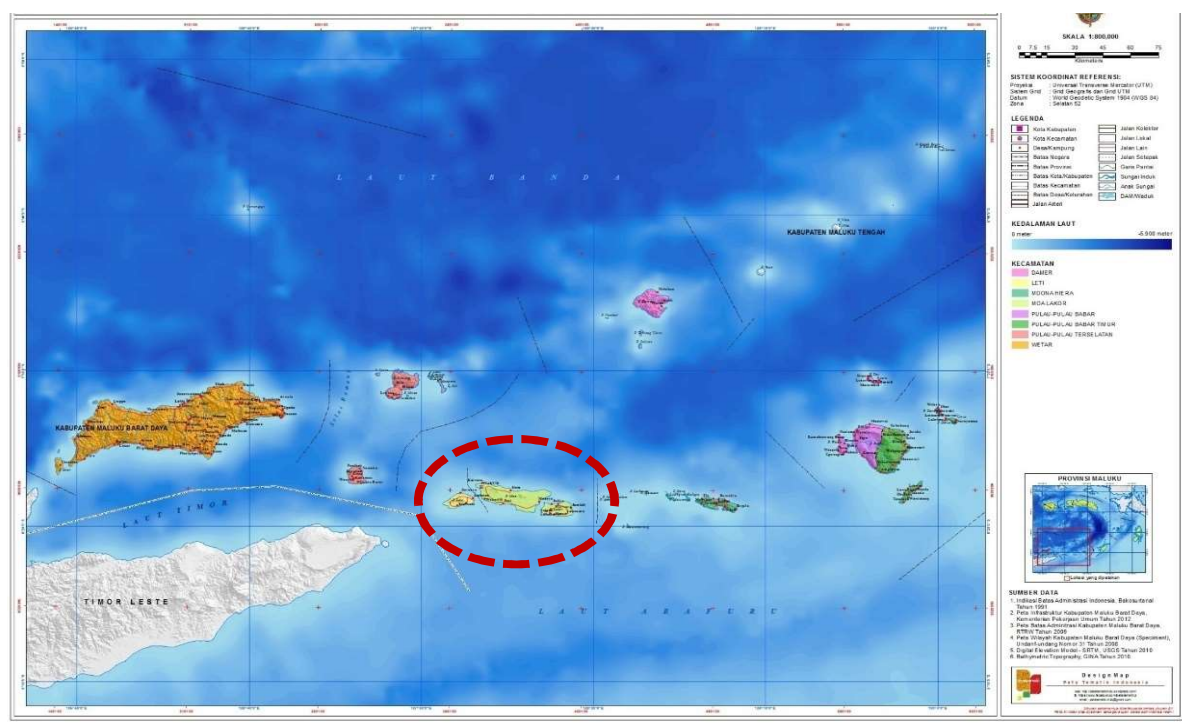

Gambar 1. Peta Lokasi Penelitian.

Data primer diperoleh melalui wawacara mendalam menggunakan topik data dengan aktor kunci dari beberapa sektor antara lain dari Dinas Kelautan dan Perikanan Kabupaten Maluku Barat Daya, nelayan dan perangkat desa untuk mengetahui akses dan kontrol pada aktivitas ekonomi kawasan SKPT. Pemilihan sampel responden dilakukan secara purposive. Purposive sampling yaitu metode pengambilan sampel yang belum diketahui jumlah responden, sehingga penentuan responden ditentukan secara subjektif oleh peneliti yang sesuai dan dianggap memiliki ciri-ciri tertentu, yang dapat memperkaya data peneliti (Pratiwi, 2015).Data sekunder dikumpulkan dari instansi terkait seperti Dinas Perikanan Kabupaten Maluku Barat Daya, BPS dan Direktorat Jenderal Pengelolaan Ruang Laut Kementerian Kelautan dan Perikanan, serta diperkaya dengan hasil penelusuran melalui publikasi dan laporan ilmiah dari lembaga penelitian dan perguruan tinggi seperti jurnal, prosiding dan laporan hasil penelitian.

Analisis data dilakukan menggunakan metode analisis data kualitatif. Analisis data kualitatif merupakan penelusuran terhadap pernyataan-pernyataan umum tentang hubungan antar berbagai kategori data, untuk membangun teori substantif yang berasal dari data yang tersedia (Marshall \& Rossman, 1989). Hal ini sejalan dengan pendapat Patton (1990), yang menjelaskan bahwa dalam penelitian kualitatif, analisis data adalah proses mengatur urutan data, mengorganisirnya ke dalam suatu pola, kategori dan satuan uraian dasar. Oleh karena itu, pekerjaan analisis data adalah mengatur, mengurutkan, mengelompokkan, dan mengkategorikan, data yang diperoleh berdasarkan keperluan terkait dengan tujuan penelitian, dan kemudian diinterpretasikan serta dikemukakan dalam deskripsi analisis.

\section{Gambaran Umum Rencana Pengembangan SKPT Pulau Moa}

Pulau Moa merupakan bagian dari Gugus Kepulauan Letti yang secara administratif termasuk dalam wilayah Kecamatan Moa. Secara geografis, Pulau Moa berada diantara Pulau Letti di bagian Barat dan Pulau Lakor di bagian Timur. Apabila dilihat secara astronomis Pulau Moa terletak pada $127^{\circ} 56^{\prime} 40^{\prime \prime}$ BT sampai dengan 08'10'59" BT, dengan luas daratan $367,82 \mathrm{~km}^{2}$ dan panjang garis pantai $100,71 \mathrm{~km}$. Pulau Moa hanya mempunyai 1 (satu) wilayah kecamatan yaitu Kecamatan Moa, yang terdiri atas 8 (delapan) desa yaitu Desa Moain, Tounwawan, Klis, Werwaru, Kaiwatu, Patty, Wakarleli, dan Kelurahan Tiakur (Badan Pusat Statistik, 2018). Serta terdiri atas 8 (delapan) dusun, yaitu Dusun Pilam, Weet, Poliu, Kiera, Watioriori, Syota, Nyama, dan Upinyor. Luas wilayah Kecamatan Moa adalah $959.68 \mathrm{~km}^{2}$. Berdasarkan BPS (2018), jumlah penduduk di Pulau Moa pada tahun 2017 sebanyak 11.003 jiwa dengan kepadatan sebesar 11,47 jiwa/ $\mathrm{km}^{2}$. Sementara itu, desa yang paling banyak jumlah penduduknya yaitu Desa Tounwawan sebesar 1.959 jiwa. Secara rinci, jumlah penduduk di Kecamatan Moa dapat diperlihatakan pada Tabel 1. 
Tabel 1. Jumlah penduduk kecamatan Moa Tahun 2015, 2016 dan 2017.

\begin{tabular}{lrrr}
\hline \multirow{2}{*}{ Desa } & \multicolumn{3}{c}{ Jumlah Penduduk (ribu) } \\
\cline { 2 - 4 } & $\mathbf{2 0 1 5}$ & $\mathbf{2 0 1 6}$ & $\mathbf{2 0 1 7}$ \\
\hline Wakarleli & 545 & 547 & 4.253 \\
Kalwatu & 774 & 777 & 1.375 \\
Patti & 619 & 621 & 735 \\
Werwaru & 657 & 660 & 711 \\
Klis & 2.141 & 2.148 & 1.725 \\
Tounwawan & 2.247 & 2.254 & 1.959 \\
Moain & 248 & 250 & 245 \\
\hline Jumlah & $\mathbf{7 . 2 3 1}$ & $\mathbf{7 . 2 5 7}$ & $\mathbf{1 1 . 0 0 3}$ \\
\hline
\end{tabular}

Rencana program pembangunan SKPT di Pulau Moa ditetapkan berdasarkan Keputusan Menteri Kelautan dan Perikanan No. 51/KEPMENKP/2016. SKPT Pulau Moa akan dipusatkan di Tiakur yang merupakan Ibukota Kabupaten Maluku Barat Daya. Lokasi SKPT ini berada diwilayah yang baru mulai tumbuh dengan pembangunan infrastruktur sekitar 5-6 tahun terakhir, sebelumnya pusat pemerintahan Kabupaten Maluku Barat Daya berada di Pulau Kisar. Pembangunan infrastrukstur dan sarana prasana umum adalah hal yang utama guna menunjang peningkatan kegiatan perekonomian. Jalan merupakan salah satu infrastruktur yang menjadi perhatian serius pemerintah daerah setempat dalam mendukung Pulau Moa sebagai lokasi SKPT. Infrastruktur jalan diperlukan sebagai sarana distribusi barang dan jasa, sarana jual beli antar kecamatan atau desa hingga pada akhirnya dapat mendukung peningkatan taraf hidup masyarakat. Panjang jalan Pulau Moa kurang lebih $80 \mathrm{~km}$ serta hampir sebagian besar jalan dalam kondisi beraspal dan hanya sedikit yang belum beraspal. Namun demikian, belum semua wilayah pesisir memiliki akses jalan dan jembatan. Hal ini sesuai dengan hasil survei lapangan, bahwa telah dilakukan pengembangan jalan di beberapa daerah namun belum maksimal. Kondisi jalan sudah lebih baik dimana sebagian jalan di beberapa daerah sudah diaspal, dan telah dilakukan pelebaran jalan. Pembangunan jalan aspal bersumber dari dana alokasi khusus pemerintah daerah setempat.

Pulau Moa telah ditetapkan sebagai salah satu lokasi program pembangunan SKPT sejak Tahun 2016, akan tetapi hingga saat ini belum ada realisasi program pembangunan dalam sektor kelautan perikanan. Namun demikian, mulai Tahun 2018, telah dilakukan penyusunan Detail Engineering Design (DED) pelabuhan Perikanan dan Pasar ikan Tiakur dengan sumber pendanaan hibah Japan International Cooperation Agency (JICA) untuk mendukung pembangunan SKPT
Pulau Moa (www.kkp.go.id). Sedangkan untuk dukungan anggaran yang bersumber dari APBN digunakan untuk mendukung operasional dan teknis SKPT, melakukan bimbingan teknis pengelola SKPT dan nelayan, serta dalam hal pengadaan bantuan operasional. Target pelaksanaan pembangunan SKPT Pulau Moa hingga akhir 2018 sampai pada tahap penyelesaian masterplan dan bisnis plan SKPT Pulau Moa.

\section{KESIAPAN SKPT MOA}

Berdasarkan tujuan dari SKPT untuk membangun dan mengintegrasikan proses bisnis perikanan berbasis kemasyarakatan berbasis masyarakat melalui optimalisasi pemanfaatan sumber daya kelautan dan perikanan di pulaupulau kecil dan/atau kawasan perbatasan secara berkelanjutan (Kepmen KP No 48/2015), maka kesiapan pembangunan SKPT Moa dalam melakukan operasionalisasi bisnis perikanan dapat dikaji dari 4 (empat) aspek yaitu infrastruktur, sarana dan prasarana, kelembagaan, dan pemanfaatan sumber daya kelautan dan perikanan sebagai berikut:

\section{Infrastruktur}

Infrastruktur merupakan komponen penting bagi pembangunan SKPT Pulau Moa. Ketersediaan infrastruktur yang baik turut mendukung perbaikan kualitas kegiatan industri perikanan dan pada akhirnya dapat meningkatkan kesempatan masyarakat dalam mendapatkan akses lapangan pekerjaan serta peningkatan distribusi barang dan jasa sektor kelautan dan perikanan. Adapun infrastruktur utama untuk menunjang kesiapan operasionalisasi SKPT Moa adalah listrik, air bersih, jalan, telekomunikasi, bandar udara dan pelabuhan.

\section{a) Listrik}

Listrik merupakan sumber energi yang sangat diperlukan untuk mendukung seluruh kegiatan yang dilakukan pada lingkup wilayah SKPT Pulau Moa. Pasokan listrik Pulau Moa saat ini disuplai oleh PLN dalam bentuk Pembangkit Listrik Tenaga Diesel (PLTD). Kapasitas listrik yang terpasang dari PLTD sebesar $5 \times 635 \mathrm{kva}$ yaitu 3125 kva (2.5 mega watt) sementara PLTS memberikan pasokan sebesar 100 kva. Namun demikian saat ini 1 unit PLTD tidak berfungsi. Sementara itu distribusi luar waktu beban puncak (Iwbp) \pm 1250 kva dan distribusi waktu beban puncak (wbp) \pm 1875 kva. 
Kriteria kondisi pasokan listrik untuk dapat menunjang kesiapan operasionalisasi SKPT Moa adalah tersedianya pasokan listrik yang stabil dan merata untuk seluruh wilayah di Pulau Moa. Sementara itu kondisi eksisting pasokan listrik di Pulau Moa berdasarkan data pasokan listrik di atas, berada pada kondisi tegangan yang kurang stabil dan sering mengalami kekurangan pasokan listrik sehingga terjadi pemadaman listrik dalam jangka waktu yang cukup lama. Untuk mendukung pasokan listrik yang memadai, direncanakan akan dilakukan peningkatan kapasitas 625 kva atau setara 0.5 mega watt. Selain itu juga dapat dikembangkan teknologi pembangkit listrik alternatif seperti mikro hidro dan PLTS.

\section{b) Air Bersih}

Air bersih merupakan komponen penting untuk menunjang operasional SKPT Moa. Dalam sektor perikanan tangkap air bersih diperlukan untuk memenuhi kebutuhan nelayan dalam proses pembersihan ikan, logistik melaut serta bahan baku dalam pembuatan es. Saat ini pasokan air bersih disuplai oleh Perusahaan Daerah Air Minum (PDAM) dari sumber mata air tanah Tiakur sebesar $700 \mathrm{~m}^{3}$ per hari dan sumber mata air di Wewaru. Dari unit produksi PDAM terdapat 1 unit pengolahan dan distribusi berkapasitas $500 \mathrm{~m}^{3}$ per hari.

Dari kondisi eksisting tersebut, pasokan air bersih di Pulau Moa belum siap untuk memenuhi kebutuhan operasional SKPT Moa. Selain itu distribusi pasokan air bersih yang tersedia belum menggunakan sistem perpipaan dan masih menggunakan kendaraan tanki air. Untuk mendukung ketersediaan air bersih yang memadai dilakukan beberapa upaya antara lain melakukan percepatan peningkatan unit produksi PDAM (Perusahaan Daerah Air Minum), percepatan peningkatan kapasitas sumber air tanah di Desa Kaiwatu dengan reservoar yang memiliki kapasitas $700 \mathrm{~m}^{3}$ per hari dengan menggunakan daya listrik dari sumber tenaga surya, serta melakukan percepatan peningkatan kapasitas kebutuhan air bersih dengan penampungan dan pengolahan air hujan (rain waterharvesting). Strategi peningkatan kapasitas air bersih dengan menggunakan teknologi rain water harvesting yaitu sesuai dengan Ali, Suharjono \& Hendrawan (2017) bahwa Sistem pemanenan air hujan (PAH) merupakan tindakan atau upaya untuk mengumpulkan air hujan yang jatuh pada bidang tadah di atas permukaan bumi, baik berupa atap bangunan, jalan, halaman, dan untuk skala besar berupa daerah tangkapan air. Pemanfaatan air hujan yang tersimpan dilakukan dengan cara konsumsi bulanan dalam memenuhi kebutuhan yang sifatnya non-potable, sehingga air yang ada dalam kolam tampungan dapat terus bersirkulasi setiap bulan selama setahunnya.

\section{c). Jalan}

Jalan merupakan infrastruktur penting untuk menghubungkan seluruh kegiatan di SKPT Moa dengan wilayah lain. Infrastruktur jalan yang baik diperlukan sebagai sarana distribusi barang dan jasa, sarana jual beli antar kecamatan atau desa dengan tujuan untuk peningkatan taraf hidup masyarakat. Kondisi eksisting jalan di Pulau Moa pada umumnya sudah cukup siap untuk mendukung operasional SKPT Moa. Hal ini ditandai dengan kondisi jalan yang mayoritas sudah diaspal serta telah dilakukan pelebaran jalan. Namun demikian masih terdapat beberapa wilayah pesisir yang belum memiliki akses jalan dan jembatan sehingga diusulkan untuk dilakukan percepatan pengembangan jalan di seluruh wilayah pesisir.

\section{d) Telekomunikasi}

Telekomunikasi merupakan salah satu faktor penting untuk mendukung kelancaran komunikasi serta kebutuhan penggunaan layanan telekomunikasi khususnya dalam operasional SKPT Moa.

Kondisi eksisting telekomunikasi di Pulau Moa saat ini masih sangat terbatas. Hingga tahun 2011 baru terdapat 1 (satu) investor penyedia jasa operator seluler yang membangun 1 tower BTS (Base Transceiver Station) di Kota Wonreli Pulau Kisar. Ketersediaan BTS yang terbatas sudah tidak dapat mencukupi kebutuhan masyarakat dalam hal komunikasi. Jaringan sering mengalami gangguan karena overload yang disebabkan oleh tingginya traffic komunikasi. Sinyal hanya tersedia di beberapa titik tertentu dan komunikasi hanya dapat dilakukan melalui layanan sms dan telepon dengan sambungan kurang lancar dan terbatas, serta sinyal internet juga sangat lambat dan terbatas. Dari kondisi eksisting tersebut, telekomunikasi di Pulau Moa belum siap untuk mendukung operasional SKPT Moa. Diperlukan penambahan BTS (Base Transmiter Station) atau sistem jaringan dan telekomunikasi untuk mendukung perbaikan sarana telekomunikasi di Pulau Moa. 


\section{e) Bandar Udara dan Pelabuhan Umum}

Bandar udara merupakan salah satu sarana akses yang sangat penting khususnya dalam mendukung operasionalisasi SKPT Moa khususnya dalam hal pemasaran hasil perikanan tangkap. Sebagai inlet ke Pulau Moa, bandara ini bermanfaat untuk mendorong aktivitas wisata, perikanan atau perdagangan ke Pulau Moa serta mampu mendorong laju pertumbuhan ekonomi dengan adanya peningkatan kemudahan pemasaran hasil perikanan dari Pulau Moa.

Kondisi eksisting di Pulau Moa saat ini terdapat 1 (satu) bandara udara umum yaitu bandara udara Jos Orno Imsula Moa yang hanya bisa diakses oleh pesawat kecil. Maskapai yang menjangkau Pulau Moa hanya Trigana Air yang melayani rute Ambon - Pulau Moa dengan jadwal penerbangan tidak dapat ditentukan karena sangat bergantung pada cuaca. Dari kondisi tersebut dapat terlihat bahwa keberadaan bandara serta jadwal penerbangan saat ini belum siap untuk mendukung operasional SKPT Moa. Oleh sebab itu rencana pengembangan bandara udara di Pulau Moa difokuskan dalam peningkatan kapasitas panjang runway, kapasitas tampung penumpang, fasilitas pendukung bandara lain dan memperbanyak rute penerbangan dari dan ke Pulau Moa khususnya yang menghubungkan daerah penghasil perikanan tangkap dan daerah pemasaran.

Sementara itu, pelabuhan umum merupakan salah satu akses transportasi yang juga penting untuk menghubungkan Pulau Moa dengan daerahdaerah lainnya. Selain itu, ketersediaan pelabuhan umum yang baik juga akan meningkatkan frekuensi kapal dan pada akhirnya turut mendukung operasional SKPT Moa khususnya dalam hal pemasaran hasil perikanan tangkap.

Kondisi eksisting saat ini di Pulau Moa terdapat satu pelabuhan umum yaitu Pelabuhan Kaiwatu, dengan intensitas kapal kurang lebih 2 (dua) minggu sekali. Pelabuhan Kaiwatu terletak di pantai utara, menjadi satu-satunya sarana pelabuhan di Pulau Moa dengan kapasitas dermaga yang masih sangat terbatas. Frekuensi kedatangan dan keberangkatan kapal masih jarang dan belum rutin.

Oleh sebab itu untuk mendukung operasional SKPT Moa, maka pada tahun 2019 direncanakan akan dilakukan percepatan pembangunan pelabuhan umum, pelabuhan polisi air, pelabuhan perikanan, dan pelabuhan ferry di pesisir Tiakur yang diharapkan dapat memperlancar arus barang dan orang (Soejarwo et al., 2018). Hal ini sesuai dengan pernyataan Putra \& Djalante (2016) yang menyatakan bahwa pelabuhan merupakan sarana yang penting terutama bagi transportasi laut, dengan adanya transportasi ini, jarak tempuh yang dibutuhkan akan terasa lebih cepat, terutama bagi perkembangan ekonomi suatu daerah dimana pusat produksi barang konsumen dapat dipasarkan dengan cepat dan lancar. Selain itu, pada bidang ekonomi, pelabuhan membawa dampak positif bagi perkembangan suatu daerah yang terisolir terutama daerah perairan dimana aksesibilitas melalui darat sulit dilakukan dengan baik.

Dari kondisi eksisting seluruh infrastruktur yang tersedia di Pulau Moa dapat terlihat bahwa mayoritas infrastruktur di Pulau Moa belum siap untuk mendukung pembangunan SKPT Moa. Sehingga diperlukan percepatan pengembangan dan pembangunan infrastruktur utama di Pulau Moa.

\section{Sarana dan Prasarana}

Pembangunan dan pengembangan SKPT Moa yang difokuskan pada bidang perikanan tentunya sangat membutuhkan sarana dan prasana pendukung. Sarana dan prasarana ini akan sangat menopang usaha ekonomi perikanan (nelayan dan pembudidaya) yang bersifat tradisional dan konvensional agar dapat berkembang menjadi bisnis kelautan dan perikanan yang mempunyai berskala ekonomi dan berorientasi pasar.

Sarana dan prasarana utama untuk mendukung operasional SKPT Moa adalah Pangkalan Pendaratan Ikan (PPI), Tempat Pelelangan Ikan (TPI), pabrik es, Integrated Cold Storage dan SPDN (SolarPackage DealerNelayan). Percepatan pembangunan dan pengembangan sarana dan prasarana kelautan perikanan secara terintegrasi yang harus didukung oleh semua pihak yang berkepentingan. Secara rinci kondisi eksisting dan kesiapan sarana prasarana pendukung SKPT Moa dijelaskan sebagai berikut:

\section{a). Pangkalan Pendaratan Ikan (PPI)}

Kriteria minimum untuk mendukung kesiapan operasional SKPT Moa adalah tersedianya fasilitas pelabuhan perikanan tipe $D$ atau Pangkalan Pendaratan Ikan (PPI) di Pantai Tiakur untuk melayani seluruh kegiatan armada perikanan yang berukuran diatas 5 hingga 20 
GT. Pengembangan PPI diarahkan untuk dapat melayani kapal berukuran lebih dari 30 GT yang beroperasi di Laut Banda. Kondisi eksisting saat ini di Pulau Moa belum tersedia fasilitas Pangkalan Pendaratan Ikan (PPI). Kegiatan pendaratan ikan dilakukan secara langsung di pesisir pantai salah satunya Pantai Tiakur. Ketersediaan dermaga sangat sederhana untuk pendaratan ikan, berlabuhnya kapal penangkap ikan $<5$ GT dan berlabuhnya speedboot untuk penyeberangan. Bentuk dermaga berupa dinding pelindung pantai, terdapat tiang pancang yang menjorok ke laut. PPI direncanakan akan dibangun di Pantai Tiakur dengan luas lahan 3.4 Ha sementara itu dermaga, jetty, couseway dan Talud direncanakan akan dibangun di lokasi area pelabuhan Tiakur dengan luas $60 \mathrm{~m}^{2}$ atau (15 x 4) m (Direktorat Jenderal Pengelolaan Ruang Laut, 2016).

\section{b). Tempat Pelelangan Ikan (TPI)}

Kriteria minimum dalam sebuah SKPT adalah terdapat Tempat Pelelangan Ikan (TPI) sebagai tempat untuk berjual beli hasil perikanan tangkap. Namun kondisi eksisting Pulau Moa saat ini belum memiliki TPI sehingga proses jual beli hasil perikanan tangkap masih langsung dilakukan di pesisir pantai Tiakur tempat hasil perikanan didaratkan. TPI direncanakan akan dibangun pada tahun 2019. Lokasi di area pelabuhan Tiakur dengan rencana luasan $300 \mathrm{~m}^{2}$ atau $15 \times 20 \mathrm{~m}$ (Masterplan SKPT MOA, 2016).

\section{c). Pabrik Es}

Kriteria minimum kesiapan SKPT Moa adalah tersedianya pabrik es yang berada di area dermaga serta TPI untuk memudahkan pengangkutan es ke kapal nelayan serta memasok kebutuhan es baik bagi nelayan yang akan melaut maupun untuk kebutuhan pembeli atau pedagang. Kondisi eksisting di Pulau Moa saat ini terdapat 2 (dua) buah pabrik es di Kecamatan Moain Pulau Moa dan di Desa Nuwewang Pulau Letti. Kapasitas masing-masing pabrik es tersebut sebesar 5 ton per hari. Kondisi kedua pabrik es tersebut dalam keadaan tidak dapat digunakan atau tidak beroperasi akibat adanya kerusakan teknis.

Lebih lanjut kedua lokasi tersebut berada jauh dengan rencana pembangunan Pangkalan Pendaratan Ikan (PPI) di Pantai Tiakur. Jarak Kecamatan Moain dengan PPI Pantai Tiakur sekitar $50 \mathrm{Km}$ atau sekitar 2 jam dengan menggunakan kendaraan bermotor, sedangkan jarak Desa Nuwewang dengan PPI Pantai Tiakur sekitar $7 \mathrm{Km}$ atau sekitar 25 menit dengan menggunakan speedboot. Kondisi eksisting tersebut terlihat bahwa sarana dan prasana pabrik belum siap untuk mendukung operasional SKPT Moa. Untuk itu, guna melengkapi kriteria minimum operasional SKPT Moa, pabrik es direncanakan akan dibangun pada tahun 2019 di PPI Pantai Tiakur.

\section{d). Integrated Cold Storage (ICS)}

Operasionalisasi SKPT Moa diprediksi sangat membutuhkan ketersediaan Integrated Cold Storage (ICS). Keberadaan sarana dan prasaran yang dimaskud merupakan salah satu kriteria minimum kesiapan operasional SKPT untuk mendukung proses pembersihan, pengemasan dan pembekuan hasil tangkapan ikan. Idealnya ICS terdiri dari Unit Pengolahan Ikan (UPI), Air Blast Freezer (ABF), Cold Storage (CS) dan Instalasi Pengolahan Air Limbah (IPAL) dimana kapasitas ICS ditentukan berdasarkan persentase volume hasil tangkapan per hari yang akan dibekukan. Luas lahan yang dibutuhkan untuk bangunan ICS di Tiakur adalah $10.000 \mathrm{~m}^{2}$ luasan tersebut sudah termasuk lahan untuk sirkulasi loading-unloading truk pengangkut, parkir truk, dan parkir kendaraan pengelola. Kondisi eksisting di Pulau Moa saat ini belum terdapat ICS. Mengacu pada road map tahun 2017 disebutkan adanya rencana pembangunan cold storage kapasitas 50 ton yang dalam perkembangannya menjadi cold storage dengan kapasitas 10 ton.

\section{e). Solar Package Dealer Nelayan (SPDN)}

Solar Package Dealer Nelayan (SPDN) merupakan sarana dan prasarana yang harus tersedia untuk mendukung kesiapan SKPT Moa. Karena ketersediaan bahan bakar merupakan hal yang sangat penting bagi nelayan untuk mendukung kelancaran aktivitas penangkapan ikan. Proyeksi kebutuhan BBM kapal perikanan tangkap tahun 2016 - 2019 di Pulau Moa disajikan pada Tabel 2.

Kondisi eksisting saat ini di Pulau Moa belum tersedia SPDN. Berdasarkan hasil proyeksi kebutuhan BBM pada Tabel 2, diperkirakan jumlah BBM yang dibutuhkan keseluruhan armada per tahunnya sebesar 974.500 Liter/tahun. Kebutuhan BBM terbesar adalah pada armada berukuran 5 GT dan 30 GT. 
Tabel 2. Proyeksi Kebutuhan BBM Kapal Perikanan Tangkap Tahun 2016-2019.

\begin{tabular}{lrrrrr}
\hline \multirow{2}{*}{ Kebutuhan BBM } & \multicolumn{5}{c}{ Penambahan Pengembangan } \\
\cline { 2 - 6 } & Eksisting & \multicolumn{1}{c}{$\mathbf{2 0 1 6}$} & $\mathbf{2 0 1 7}$ & $\mathbf{2 0 1 8}$ & \multicolumn{1}{c}{$\mathbf{2 0 1 9}$} \\
\hline Motor Tempel (<5GT) Liter/Tahun & 120.000 & 120.000 & 36.000 & 33.000 & 33.000 \\
Kapal Motor (10 GT) Liter/Tahun & 3.750 & - & 71.250 & 67.500 & 67.500 \\
Kapal Motor (20 GT) Liter/Tahun & 5.000 & - & 30.000 & 25.000 & 25.000 \\
Kapal Motor (30 GT) Liter/Tahun & - & - & 112.500 & 112.500 & 112.500 \\
\hline
\end{tabular}

Kapasitas SPDN yang harus tersedia minimal 4000 Liter/hari untuk dapat memenuhi kebutuhan BBM kapal perikanan tangkap di Pulau Moa dan direncanakan pada tahun 2019 akan dibangun di Tiakur dengan luas $48 \mathrm{~m}^{2}$ (6x8m) (Direktorat Jenderal Pengelolaan Ruang Laut, 2016). Dari kondisi eksisting sarana dan prasarana utama di Pulau Moa, dapat dilihat bahwa sebagian besar sarana dan prasarana utama di Pulau Moa belum siap untuk mendukung pembangunan SKPT Moa. Oleh karena itu, diperlukan percepatan perbaikan, pengembangan dan pembangunan sarana dan prasarana utama di Pulau Moa.

\section{Kelembagaan}

Dukungan kesiapan SKPT Moa selain dilihat berdasarkan bangunan fisik seperti infrastruktur dan sarana prasarana juga dipertimbangkan dari sisi kelembagaan. Kelembagaan diharapkan dapat melakukan pengelolaan terhadap aset produktif berupa sarana dan prasana yang akan dibangun untuk mendukung bisnis perikanan SKPT Moa. Untuk itu, dalam mempertimbangkan hal tersebut maka sebaiknya dilakukan pembentukan kelembagaan baik formal maupun non formal (kelompok dan koperasi). Strategi pengembangan kelembagaan di Pulau Moa dibagi menjadi 2 yaitu kelembagaan nelayan dan kelembagaan pengelola pelabuhan. Menurut FAO (2016) untuk melaksanakan manajemen perikanan, diperlukan kelembagaan yang sesuai dengan peraturan yang berlaku, sehingga dapat berbentuk otoritas pengelolaan perikanan. Kelembagaan yang bertanggung jawab dalam pengelolaan perikanan dapat menunjukkan bahwa negara, provinsi dan kota atau kabupaten mempunyai fungsi manajemen perikanan yang berjalan dengan baik.

\footnotetext{
Keberadaan kelembagaan nelayan diharapkan dapat meningkatkan kapasitas penangkapan ikan, memperbesar modal dan usaha agar dapat bersama merambah akses pasar yang lebih luas. Selanjutnya dalam menjaga
}

kinerja kelembagaan nelayan di Pulau Moa dapat diberikan pelatihan dan pendampingan terhadap kelembagaan tersebut (kelompok dan koperasi) guna menjalankan usaha perikanan. Hal ini mengingat kondisi masyarakat nelayan di Pulau Moa belum terbiasa berusaha secara komunal. Berdasarkan hasil survei lapang menunjukkan bahwa pada sisi kelembagaan nelayan pada sektor keuangan formal telah didukung oleh perbankan nasional seperti BRI dan BNI. Sementara itu dukungan aktif dari Kementerian Kelautan dan Perikanan dalam hal modal dan keuangan untuk memperkuat kelembagaan nelayan dan koperasi yaitu dengan mengikutsertakan Lembaga Pengelola Modal Usaha Kelautan Perikanan (LPMUKP). Sedangkan untuk kelembagaan pemasaran masih didominasi oleh papalele.

Kelembagaan pengelola pelabuhan harus segera dibentuk hal ini untuk mendukung operasionalisasi sarana dan prasarana yang akan dibangun di pelabuhan Tiakur Pulau Moa. Beberapa sarana yang akan di bangun antara lain pelabuhan pendaratan ikan, cold storage, mesin pembuat es dan SPDN. Kelembagan pengelola pelabuhan juga dapat menginisiasi kerjasama dan melakukan koordinasi lintas Kementerian dan Lembaga non Kementerian sehingga dapat dilakukan alternatif kerjasama dengan sistem KSO, service/management, Lease contract dan konsesi.

Percepatan pembentukan kelembagaan selanjutnya yaitu kelembagaan adat. Pulau Moa mempunyai adat atau kearifan lokal dalam mengelola sumber daya alam. Untuk itu agar lebih terstruktur dan mempunyai legalitas kelembagan adat harus segera di bentuk hal ini juga berperan untuk meningkatkan peran serta dan kemampuan (revitalisasi) kelembagaan adat dan budaya lokal (sasi) dalam pengelolaan sumber daya alam.

\section{Pemanfaatan Sumber Daya Kelautan dan Perikanan.}

Sumber daya kelautan dan perikanan merupakan input bahan baku untuk pengembangan 
SKPT Moa. Menurut Dinas Kelautan dan Perikanan Kabupaten Maluku Barat Daya (MBD) (2018) potensi perikanan tangkap di wilayah tersebut yaitu 105.603 ton, dengan jumlah tangkapan yang diperbolehkan yaitu 42.241 ton, sementara itu dari sisi produksi perikanan tangkap pada tahun 2017 tercatat 8.293 ton. Hal ini didukung oleh jumlah nelayan tangkap di Kabupaten MBD sekitar 4.069 orang, sedangkan untuk jumlah rumah tangga perikanan (RTP) yaitu sekitar 807 RTP. Potensi sumber daya perikanan yang besar serta tidak diimbangi dengan pemanfaatan yang optimal merupakan permasalahan yang harus segera mendapatkan solusi. Hal ini sesuai dengan pernyataan Akoit \& Nalle (2018) bahwa apabila dalam pemanfaatan sumber daya perikanan dalam kondisi underfishing yang mengambarkan rata-rata produksi aktual ikan berada di bawah rata-rata produksi maksimum lestari.

Permasalahan diatas memerlukan solusi nyata sehingga potensi sumberdaya kelautan dan perikanan dapat dimanfaatkan secara optimal, salah satunya yaitu melalui program bantuan alat tangkap yang ramah lingkungan yang sesuai dengan spesifikasi jenis ikan dan jenis armada, peningkatan kapasitas armada dan upaya untuk penangkapan tuna, penggunaan alat tangkap tuna yang ramah lingkungan seperti pancing dan tonda. Selain itu juga sangat dibutuhkan adanya pelatihan dan pendampingan dalam operasionalisasi armada dan alat tangkap.

Lebih lanjut dalam hal pemanfaatan sumber daya kelautan dan perikanan dapat dilakukan strategi pengelolaan sumber daya ikan pada tingkatan Wilayah Pengelolaan Perikanan (WPP) perlu dilakukan sosialisasi, komunikasi serta konsolidasi dengan Pengelola WPP 714 di tingkat regional dan tingkat provinsi Maluku Tenggara tentang kebijakan SKPT dan pemanfaatan sumber daya ikan di SKPT Moa.

\section{PENUTUP}

Untuk mendukung kesiapan Pulau Moa sebagai wilayah SKPT perlu segera dilakukan pengembangan dan pembangunan yang meliputi infrastrukturdan sarana prasarana. Pada sektor infrastruktur perlu mendapatkan peningkatan kapasitas, fasilitas dan kualitas untuk mendukung percepatan operasionalisasi SKPT Moa. Sementara itu pada sektor sarana prasarana pendukung
SKPT Moa sangat perlu dilakukan percepatan pembangunan hal ini dikarena sebagian besar belum tersedia. Pada aspek kelembagaan perlu dilakukan penguatan dalam hal kerjasama dan melakukan koordinasi lintas Kementerian dan Lembaga non Kementerian. Pembentukan kelembagaan adat yang berperan sebagai pengelolaan sumber daya alam perlu dilakukan. Aspek pemanfaatan sumber daya kelautan perikanan terkait dengan komoditas sumber daya kelautan perikanan ekonomis yang belum bisa dimanfaatkan secara optimal karena penggunaan alat tangkap yang sederhana serta mayoritas armada kapal penangkap ikan yang masih berukuran kecil (sekitar 1-5 GT).

Secara keseluruhan, berdasarkan pembahasan strategi percepatan dalam menunjang pengembangan dan pembangunan SKPT Moa terhadap aspek infrastruktur, sarana prasarana, kelembagaan, pemanfaatan sumber daya kelautan dan perikanan dapat memberikan dampak positif untuk Kabupaten Maluku Barat Daya dalam hal: 1) Membuka lapangan kerja baru bagi para pekerja yang ada di kawasan SKPT Moa karena adanya ICS (Integrated Cold Storage) dan tempat pendaratan ikan; 2) Meningkatkan pengetahuan nelayan atau pekerja setempat terhadap literasi teknologi pendingin untuk proses pendinginan dan penanganan ikan (termasuk tuna) di SKPT Moa; 3) Potensi terjadinya peningkatan nilai ekonomi nelayan penangkap tuna untuk pemasok ICS (Integrated Cold Storage) di SKPT Moa. 4) SKPT Moa dapat menjadi pemicu kegiatan-kegiatan ekonomi lain penunjang sektor perikanan seperti pengadaan alat tangkap, bahan pokok makanan, dan kebutuhan input lainnya untuk keperluan penangkapan ikan.

\section{UCAPAN TERIMA KASIH}

Ucapan terima kasih penulis sampaikan kepada BBRSEKP yang telah memberikan pendanaan pada kegiatan penelitian ini. Kepada Tim SKPT Moa yang telah bekerjasama dalam menyelesaikan penelitian ini. Serta ucapan terima kasih penulis disampaikan kepada Direktorat Jenderal Pengelolaan Ruang Laut (DJPRL) - KKP yang telah bersama-sama melakukan survei, kepada Dinas kelautan dan Perikanan Kabupaten Maluku Barat Daya dan Penyuluh Perikanan Bantu-KKP yang telah membantu dalam hal data dan informasi selama kegiatan penelitian ini berlangsung. 


\section{DAFTAR PUSTAKA}

Ali, I., Suharjono. \& Hendrawan, A.P. (2017). Pemanfaatan Sistem Pemanenan Air Hujan (Rainwater Harvesting System) Di Perumahan Bone Biru Indah Permai Kota Watampone Dalam Rangka Penerapan Sistem Drainase Berkelanjutan. Jurnal Teknik Pengairan, Vol 8. No 1 Hal 26-38

Akoit, M. Y. \& Nalle, M. N. (2018). Pengelolaan Sumber daya Perikanan Berkelanjutan di Kabupaten Timor Tengah Utara Berbasisi Pendekatan Ekonomi. Jurnal Agribisnis Indonesia, Vol 6 No 2, halaman $85-108$

Badan Pusat Statistik. (2014). Provinsi Maluku 2014 Dalam Angka. Jakarta

Badan Pusat Statistik. (2018). Kecamatan Moa Dalam Angka 2018. Jakarta

Dinas Kelautan dan Perikanan Kabupaten Maluku Barat Daya. (2018). Potensi dan Produksi Perikanan Kabupaten Maluku Barat Daya. Kabupaten Maluku Barat Daya

Direktorat Jenderal Pengelolaan Ruang Laut. (2016). Masterplan dan bisnisplan SKPT MOA 2016. Jakarta: Kementerian Kelautan dan Perikanan.

Direktorat Jenderal Pengelolaan Ruang Laut. (2018). Laporan Identifikasi Potensi Ekonomi Maluku Barat Daya, 2018. Jakarta: Kementerian Kelautan dan Perikanan.

[FAO] Food and Agriculture Organization Of The United Nations. (2016). Caribbean Fisheries Legal And Institutional Study: Findings of The Comparative Assessment and Country Reports. Bridgetown, Barbados.

Hendri. (2010). Peran Sektor Perikanan dalam Perekonomian dan Penyerapan tenaga kerja di Provinsi Sumatera barat: Analisis Input Output. Tesis Program studi perencanaan pembangunan. Universitas Andalas Padang

KKP. (2018). Gambar Pendukung SKPT. https://kkp. go.id/an-component/media/upload-gambar pendukung/SKPT/F oto/Struktur\% 20 Organisasi\%20SKPT.jpg. Diakses pada tanggal 4 Oktober 2018

Maritime News. (2018). 20 Prioritas SKPT. https:// maritimenews.id/wp-content/uploads/2018/08/ x 20 -Prioritas-SKPT.jpg.pagespeed. ic.bjgihLvuY9.jpg. Diakses pada tanggal 3 Oktober 2018.

Marshall C. \& Rossman G.B. (1989). Designing Qualitative Research. Newburry Park, CA: SAGE.

Neuman, W.L. (2003). Social Research Methods, Qualitative and Quantitative Approaches. Fifth Edition. Boston: Pearson Education.
Patton, M.Q. (1990). Qualitative Evaluation Methods. Beverly Hills: SAGE.

Putra, A.A. \& Djalante, S. (2016). Pengembangan Infrastruktur Pelabuhan Dalam Mendukung Pembangunan Berkelanjutan. Jurnal IImiah Media Engineering, Vol.6 No.1 (433-4).

Pratiwi, S. (2015) "Pengembangan Model Konseptual Penerapan Pupuk Organik pada Pertanian dalam Skema Pengelolaan Sampah Terdesentralisasi dengan Pendekatan Whole System". Tesis, ITB Bandung, 2015

Riyadi, D.M.M. (2000). Pembangunan Deaerah Melalui Pembangunan Wilayah. Diseminasi dan Diskusi Program-Program pengembangan wilayah dan pengembangan ekonomi masyarakat di daerah. Bogor. Jawa Barat.

Soejarwo, P. A., Muawanah, U., \& Yanti, B. V. I. (2018). Upaya Percepatan Operasionalisasi Sentra Kelautan Dan Perikanan Terpadu (SKPT) Kabupaten Maluku Barat Daya - Pulau Moa. Balai Besar Riset Sosial Ekonomi Kelautan dan Perikanan - BRSDMKP - Kementerian Kelautan dan Perikanan. Jakarta.

Suman, A., Wudianto., Sumiono, B., Badrudin \& Nugroho, D. (2014). Potensi dan Tingkat Pemanfaatan Sumber daya Ikan Di Wilayah Pengelolaan Perikanan Republik Indonesia (WPP RI). Ref Graphika dan Badan Penelitian dan Pengambangan Kelautan dan Perikanan. Jakarta.

Trobos. (2018). KKP Bangun 20 SKPT di Seluruh Wilayah Indonesia. http://www.trobos.com/ detail-berita/2018/01/31/56/9808/pembangunan-20-skpt-pulau-terluar-6-hibah-dari-jepang. Diakses pada 4 September 2018.

Wardono, B., Muhartono, R., Hikmayani, Y., Apriliani, T., Hikmah., Sari, Y.D., Erlina, M.D., Muawanah, U., Muliawan, I., Firdaus, M., Yuliati, C., Yanti, B.V.I., Kurniawan, T., Soejarwo, P.A., Putri, H.M., \& Noviardy. (2017). Riset Model Integrasi Ekonomi Dalam Mendukung Percepatan Industrialisasi Perikanan Nasional. Balai Besar Riset Sosial Ekonomi Kelautan dan Perikanan - BRSDMKPKementerian Kelautan dan Perikanan. Jakarta. 